\title{
MODELING PIPELINE PROJECTS USING COMPUTER SIMULATION
}

\author{
Hany Zahran \\ School of Science and Engineering \\ American University in Cairo (AUC) \\ Cairo, EGYPT
}

\author{
Khaled Nassar \\ School of Science and Engineering \\ American University in Cairo (AUC) \\ Cairo, EGYPT
}

\begin{abstract}
Due to The increasing demand on fossil fuel, Pipelines have become an essential element in today's world economy. Thus, any delays in pipeline construction projects have become highly intolerable. The construction process has many activities that involve various resources and each activity relies strongly on its predecessors. This paper presents a tool for planning pipelines projects using computer simulation. The proposed tool aids contractors in planning pipelines projects by estimating their associated time and cost of construction. The tool breaks down pipeline projects into a number of activities along with their resources. An application example is presented to demonstrate the features of the proposed tool.
\end{abstract}

\section{INTRODUCTION}

Pipelines are used to transfer oil and gas among other materials for long distances across political borders and geographic obstacles. In spite of the large construction costs, it is considered more economic and fast solution for transportation than other methods of transportation. Pipeline construction process is performed repetitively on segments. One of the main problems that pipeline construction faces is resources allocation optimization. Any shortage in any resource during the operation would cause a total delay to the project total duration; therefore, each resource size should be studied carefully in order to reach the best time-cost trade-off.

A construction operation usually consists of different construction processes; therefore, the flows between the processes and the resource utilizations of the processes could directly affect the performance of the construction operation. To better understand the performance of the construction operation, construction project planners can use computer simulation to predict the performance of the construction operation in terms of process flows and resources utilization. In the construction domain, there are several custom developed simulation packages specially designed for applications in construction projects. Those simulation packages include MicroCYCLONE, INSIGHT, RESQUE, COOPS, STROBOSCOPE, and COST, all based on CYCLic Operation NEtwork (CYCLONE) developed by Halpin (1977).

However, with these simulation tools, to find the best resource utilization of the construction operation, all possible resource combinations need to be tested within the simulation process. That is, a socalled sensitivity analysis, an exhaustive enumeration of resource combinations should be conducted, which could be extremely time-consuming, if possible resource combinations increase explosively. Therefore, traditional simulation is not considered as an optimization technique. Hence, an optimization technique such as Genetic Algorithms or Particle swarm should be utilized to reach the optimum solution.

There is no previous similar research in this point. However, hybrid models utilizing both simulation tools and optimization techniques were developed to solve many problems.

A number of simulation optimization techniques have been described in the literature (Shi and AbouRizk 1995; Carson and Maria 1997; Azadivar 1999). Marzouk and Moselhi (2004) developed a 
model used in earth moving projects. Hegazy and Kassab (2003) proposed an approach that determines the least costly, and most productive, amount of resources that achieve the highest benefit/cost ratio in individual construction operations. The resource optimization system was demonstrated in two case studies: Concrete placing and Earth moving problems. Other examples were illustrated such as concrete operations (Hassan and Gruber 2008), bridges (Marzouk et al. 2006), and tunnels (Tanaka 1993; AbouRizk et al. 1999).

In the next section, the construction methods of pipelines would be demonstrated. It will be followed by explanation of the proposed tool. Next, an example would be presented to exhibit the model's capabilities. Last, the conclusions of this study would be presented.

\section{PIPELINE CONSTRUCTION METHODS}

A pipeline can be broken down into three basic elements where different forms of pipeline construction method are used. They are:

(i) Open cross-country areas, where the spread technique is used

(ii) Crossings, where specialist crews and civil engineering techniques are used

(iii) Special sections such as built up urban areas, restricted working areas, difficult terrain sections and environmentally sensitive areas.

The basic method of constructing steel, welded oil and gas onshore pipelines in open cross country areas is generally known as the "spread technique". The spread technique utilizes the principles of the production line system, but in the case of a pipeline the product (the pipeline) is static and the individual work force, (crews) move along the pipeline track. The implementation of the spread technique is conditional on the pipeline being welded above ground in maximum possible continuous lengths between obstructions/crossings, which can extend to lengths in excess of 10 kilometers. These welded pipe lengths are then immediately installed into unsupported/unobstructed trenches gradually in one continuous length utilizing multiple (three or more) mobile lifting tractors (side-booms) together. The breaks in the continuous main spread method of working result from the location of existing services, roads, railways, tracks, ditches, streams and river crossings, and are also dependent upon restricted working, time constraints and physical features/obstructions. These breaks in the main pipeline spread activities are undertaken by dedicated specialist crews utilizing a variety of special construction techniques and are generally undertaken after the main pipeline sections have been installed.

The main pipeline spread installation is undertaken by dedicated crews undertaking one operation at a time commencing at one end of the pipeline and travelling forward to the other end at anything from $500 \mathrm{~m}$ to $1,500 \mathrm{~m}$ per day depending on the diameter of the pipe, terrain, soils, etc. The program of activities and the start-up of the crews is dependent on available resources and the risk of one crew having an impact upon the following activities.

Pre-construction activities need to be carried out by the Installation Contractor prior to the start of the main pipeline installation activities. These activities include finalizing the pipeline route, detailed design finalization, mobilization, notification of entry to landowners, setting-up of pipe yards and base camps, establishing temporary works requirements, setting-up of geographic positioning stations, design of land drainage in agricultural areas and reinstatement works, construction of temporary access roads, preenvironmental mitigation works, and agreeing with landowners any special requirements prior to entry onto their properties. The Installation Contractor will carry out pre-entry surveys as-and-where required so as to record the condition of the land prior to the start of any work.

Once the pre-construction activities have been completed, then the main construction works can commence. Generally, operations are carried out in three main activities groups as shown in figure 1:

1. Preparing Work Area

2. Layout Pipe and Weld above Ground 
Nassar

3. Excavate Trench and Installation of Pipe

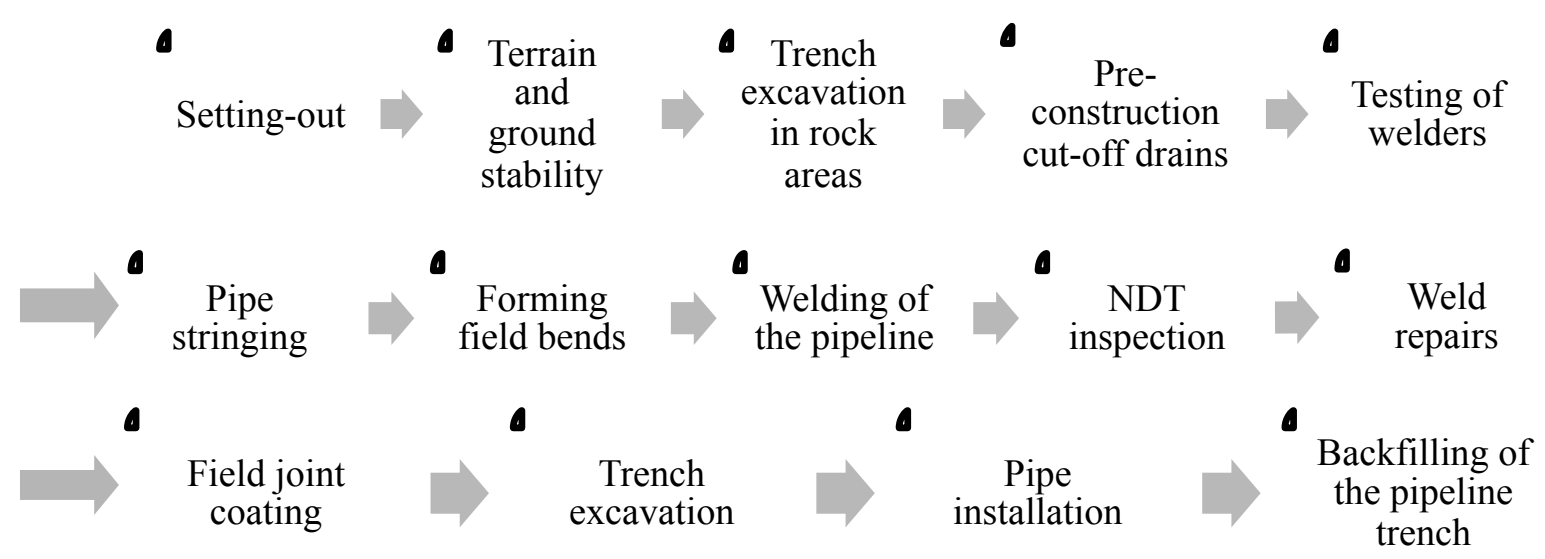

Figure 1: The flowchart of spread method activities

The first group which is Preparing Work Area contains many operations, First, Setting-out. The setting out of the works should be scheduled to commence at least four weeks prior to the remainder of the first group activities. This work will be carried out with small four man crews using GPS and surveying instruments. Setting-out pegs will be placed at all boundaries, changes in direction and intermediate sightings on the proposed centre line and the extremities of the working easement. Initial ground investigations works will be carried out directly behind the setting-out crew. Part of the setting-out crew's duties is to identify any existing services that cross or are in close proximity to the pipeline and supervise the trial hole crew. The trial hole crew will hand excavate to expose, identify and determine the exact location of all existing services. This data will be recorded and transferred to the engineers for incorporation into the final pipeline design.

The second activity is Pre-construction terrain and ground stability. At locations where there is a risk of ground movement that could result in safety risks to the construction activities and/or undermine the pipe during installation and the period prior to final reinstatement then permanent stability of the affected terrain needs to be undertaken. This work can be separated into two elements; first, Removal of material such as the overburden at the top of ravines and the removal of loose material that could move during the installation works and second, Addition of material such as Bentonite, which is injected under pressure into gravels with high and fast water tables and deep mining areas to provide a protective curtain around the pipe. It also includes the adding (placement) of boulders/ground at the toe of steep gradients on forwarded and side slopes in the second element.

The third activity is Trench excavation in rock areas. In areas where rock is confirmed as such by the initial ground investigation works then the trench is excavated ahead of any pipe operations. This sequence of working is undertaken to ensure that the excavation of the trench cannot cause any damage to the pipe and/or pipe coating and provide an extended safe working width for the excavation crews allowing double-sided trench working by excavators/ breakers.

Following the review of the data from the initial ripper and trial hole surveys, the ground will be classified in ease of excavation into five groups defined by the method of removal. These are (i) utilizing standard excavation, (ii) larger more powerful excavators (face shovels converted to back-actors), (iii) ripping/hydraulic hammer and excavation, (iv) blasting/hydraulic hammer and excavation and (v) rock trenchers (saw and blade). The finished trench should be to the correct depth and width to suite the pipe diameter, plus any bedding and pipe cover. The trench should also be in a straight line so that the pipe can lay central in the trench without coming into contact with the trench sides. All loose and jagged outcrops, 
which could come in contact with the pipe during lay operations, will be removed. The excavation will commence with dedicated crews immediately following the ROW operation. The forward progress will be dependent upon the ground strength, grain structure, terrain, access, method of removal and number of crews/equipment employed.

The fourth and last activity is Pre-construction cut-off drains. All cut-off drainage works, which comprise the connection of existing drains to a new header pipe, will commence immediately after the right of way and fencing operations. Cut-off drainage works will be undertaken at locations where there are existing concentrated drainage schemes on agricultural land and where agreement is reached with the landowners and/or occupiers to their installation. This work will be resourced taking account of the scope of work and the requirement to achieve pipeline installation progress of, say, 500 to 1,500 meters per day along the pipeline route.

The second group of activities is layout pipe and weld above ground. The first activity is Project mechanical procedures/testing of welders. Once the documented procedures are approved then full trials for each element of the works will be carried out, fully inspected and witnessed by the Client. The welding will include non-and full destructive testing to ensure that the procedure welds are undertaken in strict compliance with the contract requirements and fully comply with the minimum strength, hardness and quality requirements of the relevant specifications. Once the procedures have been approved then the welders will be tested to ensure that they can comply with the requirements of the procedure welds. A register will be maintained of the welders employed on the project with the various welding techniques they are approved to work on.

The second activity is Pipe stringing. The pipes and pre-formed bends will be scheduled to be delivered to, and stock piled at, the proposed pipeline pipe yards some 4 to 8 weeks in advance of stringing operations. Immediately following ROW or topsoil strip or excavation in rock areas, the pipe stringing operations will commence, which involves laying the pipe lengths along the easement length using pipe trailers. A typical crew will consist of two cranes - one at the base camp loading the pipe trailers and the other on the pipeline easement off-loading the pipe trailers. In the event that ground conditions do not permit travel down the easement with standard or special heavy-duty pipe trailers then the pipes will be loaded on to tracked pipe carriers at the public roads or at a point where the change in ground conditions occurs and permits the turning of the wheeled pipe trailers.

The third activity is forming field bends (cold bending). Once the pipe has been strung along the easement, engineers will follow to determine the location of all bends required in order that the pipeline can follow the contours of the land and the required line and level as detailed on the drawings. There are two types of bends normally used i.e. hot pre-formed or forged bends which are manufactured off site in a factory and are to a radius of 5 or 3 times the pipe diameter and cold bends which are to a radius of 40 times the pipe diameter and are formed in the field. A typical cold bending crew consists of a four-man team together with a bending machine and a side boom tractor. The bending machine is towed along the pipeline route by the side boom and includes "formers" consisting of $20-150$ ton hydraulic rams, which bend the pipe to the required radius and angle. The side boom acts as a lifting device and has a fixed jib attached to a tracked dozer with a capability of lifting between 15 to 120 tons, dependent upon the size of the machine used. The number of cold bends required depends on the route and contours of the pipeline. Typically, they can range from 1 pipe in 10 in developed regions to 1 pipe in 50 in open country. The cold bend angle that can be achieved ranges from maximum angles of 12 degrees (42" pipe) to 40 degrees (12" pipe).

The fourth activity is Welding of the pipeline. The welding of the pipeline will commence a few days after the cold bending crew. The welding crew will weld the pipeline in continuous lengths between features such as roads, watercourses, tracks, railways, services and other underground obstacles that prevent the pipeline being continuously installed in the trench. There are primarily two methods of welding which are manual or automatic. As the names imply manual welding involves the welding of the pipe by welders 
and automatic involves a semi-automatic system. Both systems generally (although certain automatic systems can now do single pass complete welds) operate on a front-end/back-end principle. The front-end consists in a manual operation with, say, 3 separate welding stations placed on CAT D6 carriage consisting of a HIAB for the welding shelter (used in inclement weather or windy conditions), 4 welding bullets and a compressor. The welding stations work on 3 separate joints and complete one pass before moving on with the sequence being the bead ( 2 - 4 welders), immediately followed by the hot pass $(2-3$ welders) and then hot fill ( 2 welders). With the automatic process, 1 machine deposits sufficient weld metal equivalent to the 3 manual passes. The weld is allowed to cool after the front-end passes and then sufficient welders working in pairs or multiple automatic machines follow on to fill and cap that day's production. The crew will achieve progress in the order of one weld approximately every 3 to 5 minutes or up to 90 to 150 welds per day, which is equivalent to 1,000 to 1,500 meters of pipeline on 12 meter pipes and up to twice that if double -jointed pipes are used.

The fifth activity is Non Destructive Tests (NDT) inspection. All welds on the pipeline are generally subjected to inspection by radiography. This is achieved on the main pipeline by an internal x-ray tube travelling along the inside of the pipe carrying out $\mathrm{x}$-rays at each weld for approximately 2 minutes per weld. On completion of the x-ray the film is taken to a dark room and processed in time for the results to be available for inspection at the end of the day or early the next day. Welds, which do not meet the required acceptance criteria, are either repaired or cut out and re-welded. Experienced and qualified x-ray specialists undertake the radiography under controlled conditions. Before the operation is started, the section of pipeline is cordoned off by marker tape to stop entry by non x-ray personnel and audio/flashing warning alarms are activated during all times when the x-ray tube is energized. The x-ray personnel are on constant surveillance to ensure that the workforce and members of the public are aware of the x-ray activities and only authorized access is permitted. Welds completed by semi-automatic welding processes are examined using automatic ultrasonic testing (AUT) techniques. This consists of an assembly that traverses the circumference of each completed weld in order to detect any defects. The results of each ultrasonically inspected weld are automatically recorded and are used to determine whether a weld repair is required and if so what type.

The sixth activity is Weld repairs. A weld repair crew follows immediately behind the NDT inspection activities to either carry out repairs to or cut out any defective weld. On completion of all repairs a further x-ray is carried out on the weld to ensure that the finished weld conforms to the standard required. The x-ray of repair welds is usually carried out from the outside of the weld by a two-man crew.

The last activity is Field joint coating. The coating of the pipeline field joints to prevent corrosion starts a few days after the welding. This extended period is to allow for any repairs or cut-outs to be completed without prejudicing the coating crew's operations.

The third group of activities is excavation of trenches and installation of pipes. The first activity is Trench excavation. In areas other than rock, trench excavation commences a few days after the field joint coating operation. A typical trench excavation crew consists of 5 - 8 excavators working in line. This operation only excavates the length of open cut trench sufficient to install the main line welded pipe; it does not excavate any roads, ditches, services or obstacles. The number of excavators employed will be such that the amount of trench excavated in a single day matches the rate of progress of the welding crew. The spoil from the trench will be stored adjacent to the trench on the opposite side of the ROW from the topsoil stack. The finished trench will be to the correct depth and width to suit the pipe diameter, plus any bedding and pipe cover. As far as possible, the trench should also be in a straight line so that the pipe can lay central in the trench without touching the trench sides. All loose and jagged outcrops, which could come into contact with the pipe during laying operations, will be removed.

The second activity is Pipe installation. The pipeline will be positioned approximately 5 meters from the trench centre-line and will be installed into the open unobstructed trench utilizing a number of sidebooms. This operation will usually be carried out immediately following the excavation crew. As the 
pipeline is being installed a coating crew will be present who will holiday detect the pipe to detect any damage to the pipe coating just prior to the pipe entering the trench. Any damage detected will be repaired by a fast setting repair coating. In areas of rock, the pipe installation will commence anything from 5 to 15 days after the welding crew. If there are any above ground breaks in the mainline due to access openings across the ROW, expansion breaks or bend breaks, then these will be welded above ground, $\mathrm{x}$ rayed and coated during the excavation and lowered-in as part of the mainline lower \& lay operation. This will optimize the use of the side-booms within the lower \& lay crew and reduce the number of below ground tie-ins.

The last activity is Backfilling of the pipeline trench. Trench backfill starts immediately following the placement of the pipeline in the trench and the undertaking of a survey of the pipe levels by the engineers to confirm that the required pipe cover has been achieved. There is a requirement that the initial backfill around the pipe and to $300 \mathrm{~mm}$ above the crown be of loose and relatively fine particles, which can be readily compacted and do not damage the pipe coating. In areas of rock it will be necessary to place the pipe on a $150 \mathrm{~mm}$ bed of similar material. In order to provide this material it may be necessary to import sand/soft material offsite, sieve the excavated material or crush the excavated material. The sieve and crusher equipment will be portable machines, which will be transported along the pipeline ROW. The pipe is backfilled over the entire length except for, say, 30 meters at each end of the pipeline work section, which is left free to facilitate the tie -in to the crossing/line break pipe work.

\section{THE PROPOSED TOOL}

The proposed tool aids contractors in planning pipeline projects by estimating the total cost and duration of construction. The simulation module is responsible for estimating duration and utilization of resources in each segment in the project. It utilizes EZStrobe as a general purpose simulation engine.

EZStrobe is a very simple but powerful general-purpose simulation system designed for modeling construction operations, but domain independent and thus useful for modeling a wide variety of systems in any discipline. EZStrobe is based on Activity Cycle Diagrams and employs the Three-Phase Activity Scanning paradigm. It is therefore naturally intelligent for complex systems where many resources collaborate to carry out tasks as is typical in construction.

In EZStrobe models, all activity startup conditions and outcomes are in terms of resource amounts. Resources that reside in the same location are assumed to be indistinguishable, interchangeable, and exist in bulk quantities. EZStrobe does not enforce the type of resources and the units with which they are measured; the modeler is responsible for maintaining consistency. Martinez (2001)

The proposed model consists of many activities as in figure (6). The relationship between them is finish to start or start to start. The first activity is surveying works. This activity draws one resource from several queues which are "Survy_Teams" queue, "GPS_Dvc" queue, "Tt1S_Dvc" queue, "Points1" queue and "Points2" queue. It sends one resource to "Bnchmrk1" and "Bnchmrk2" queues.

The second activity is earth works which represents clearing the ground prior to construction of access roads. The activity draws one resource from "Loaders" queue, "Trucks1" queue, "Soil" queue and "Finished2" queue, which is a dummy queue that stands for finishing surveying works. It sends one resource to "Dumpd_Soil" queue. Filling this queue would allow the next activity to start. The next activity includes loading, hauling and stringing the pipes along the planned route. The activity relies on many resources which are "Pipes" queue, "Cranes1" queue, which are located in the pipe yard, "Trucks2" queue and "Cranes2" queue, which are in the construction site. The output of this activity would be stored in "Laid_Pipes" queue.

The next activity is welding pipes and inspecting the weld integrity. The activity draws from "Laid_Pipes" queue, "Cranes2" queue, "WeldCrews" queue and "Inspect_Crews" queue. The outcome of the activity is accepted welded pipes and they are stacked in "Accepted" queue. The last activity compris- 


\section{Nassar}

es excavating trenches, lowering the pipes in the trenches and backfilling the trenches. The activity depends on many queues such as "Soil2" queue, "Excavators" queue, "Cranes2" queue, "Accepted" queue and "Loaders" queue. This activity's result is stored in "Finish_Segments" queue. The simulation model is presented in figures (7), (8), (9) and (10).

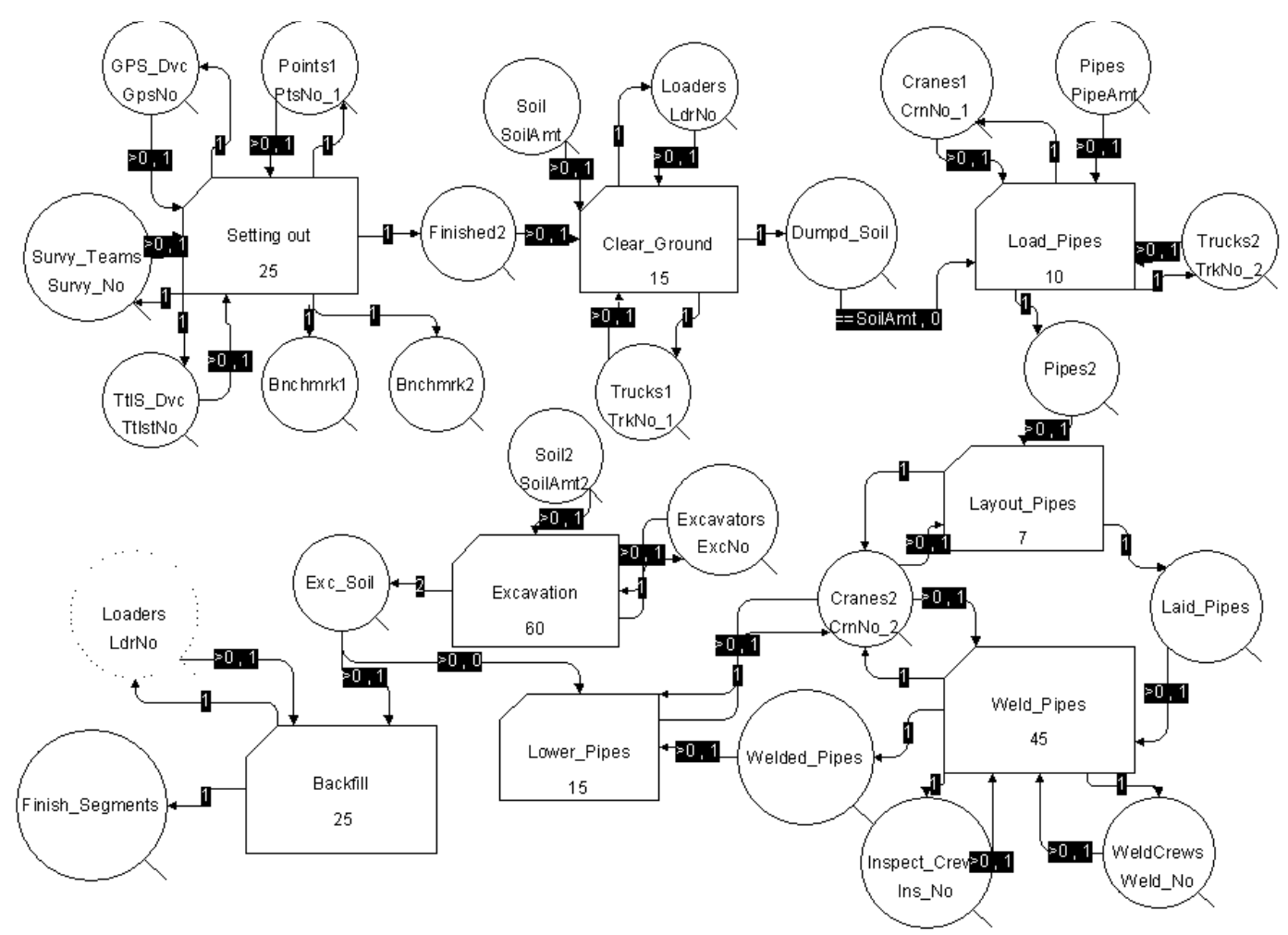

Figure 6: Schematic model for pipeline construction 
Nassar

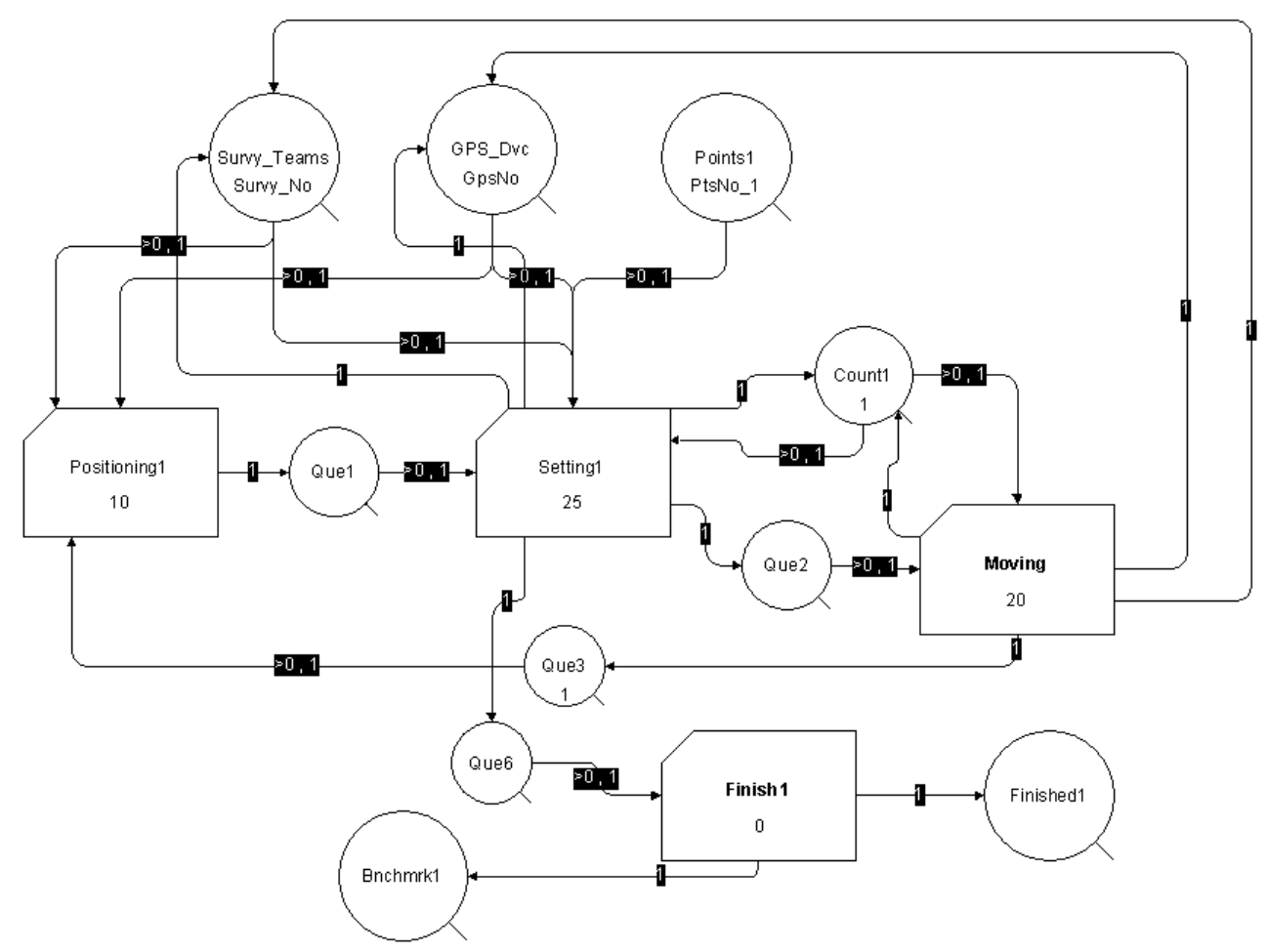

Figure 7: Simulation model for pipeline construction-part 1

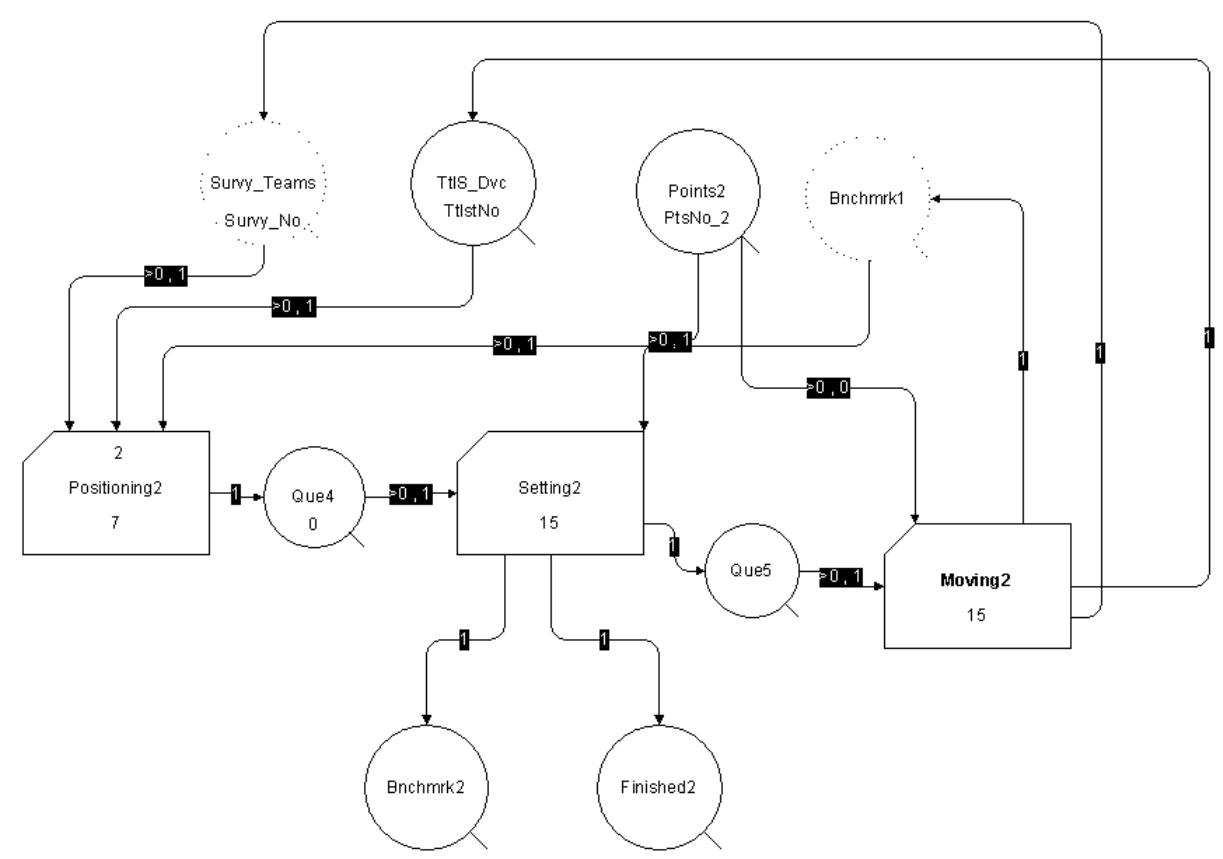

Figure 8: Simulation model for pipeline construction-part 2 
Nassar

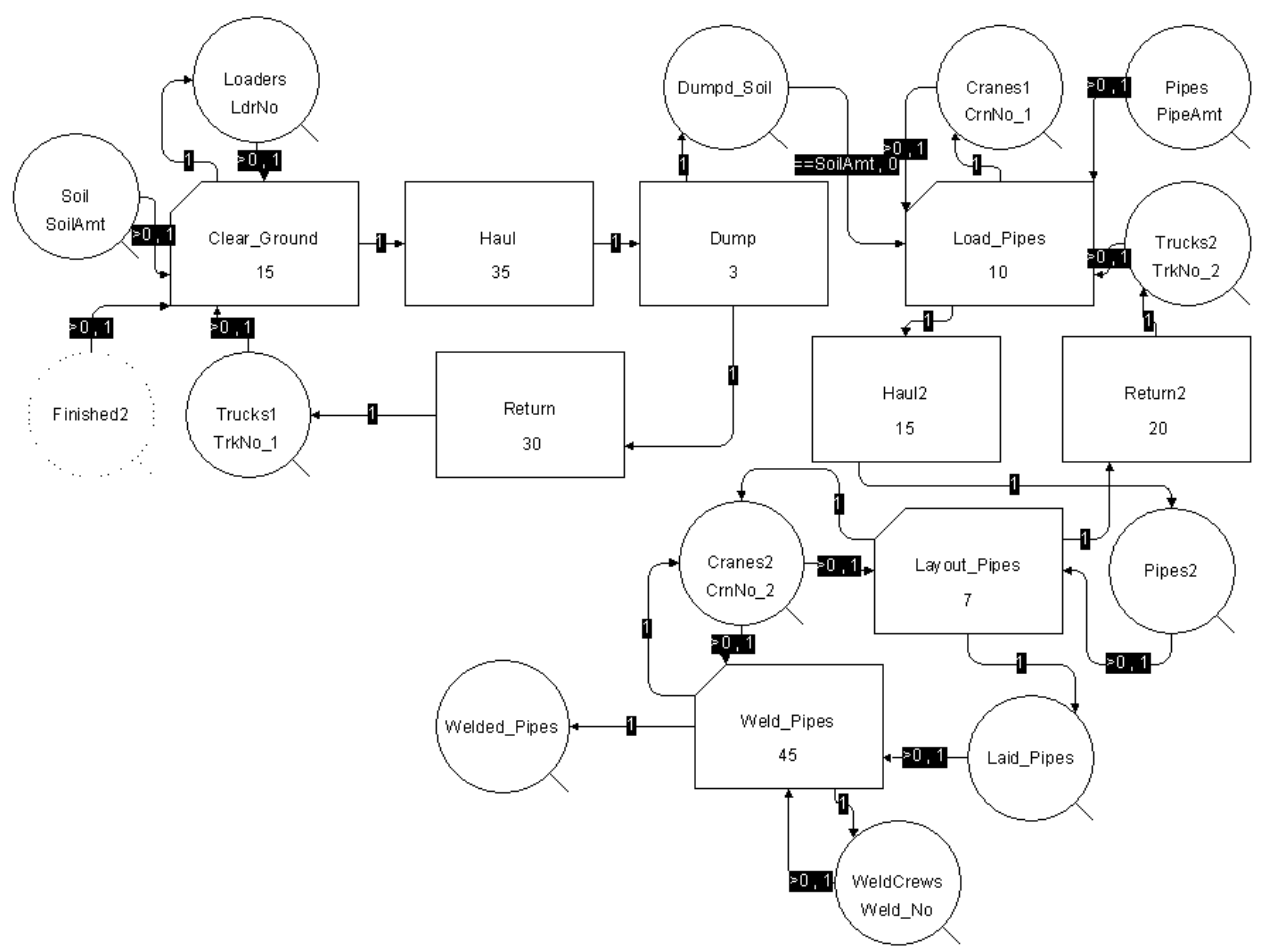

Figure 9:Simulation model for pipeline construction-part 3 


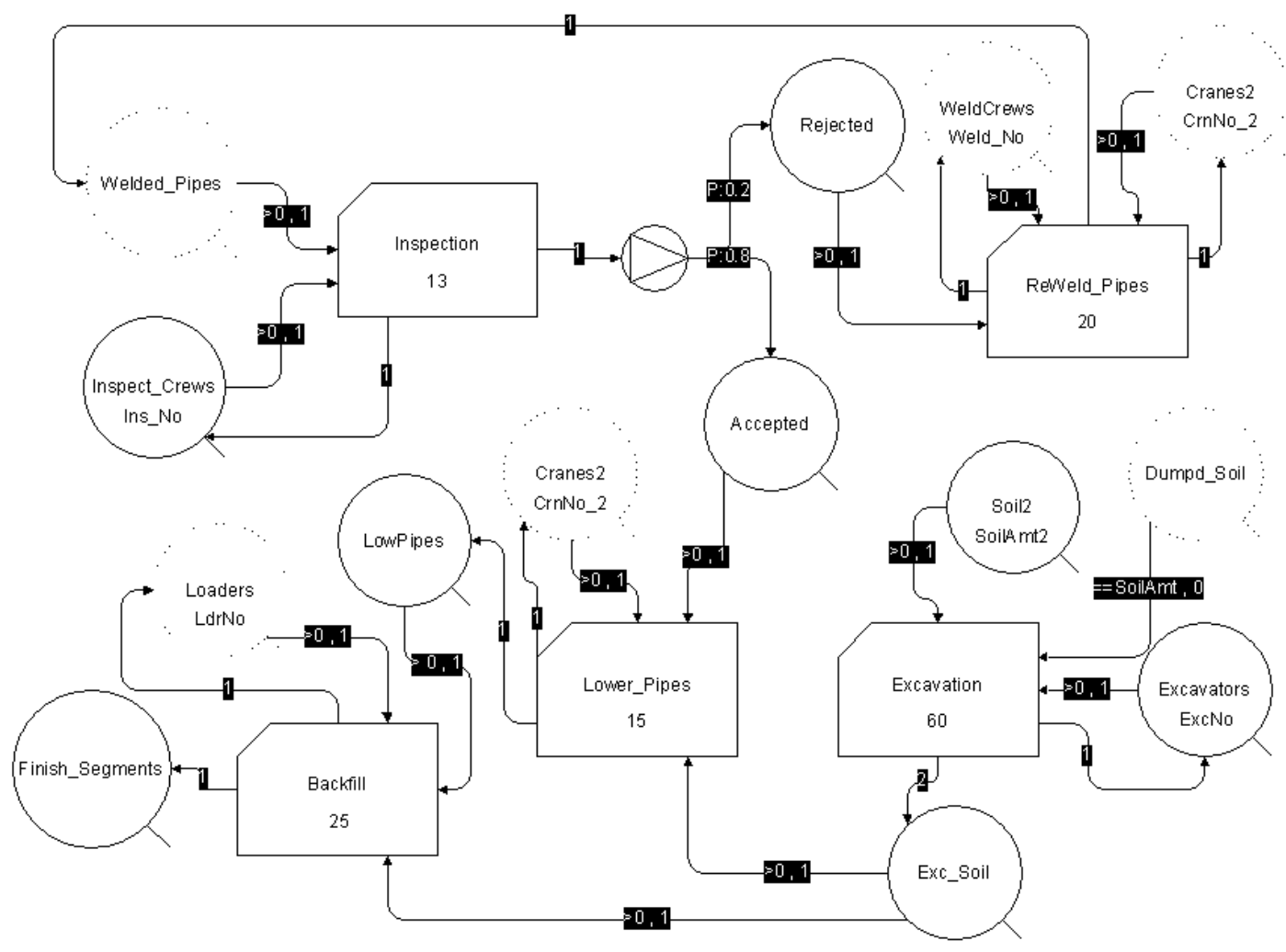

Figure 10: Simulation model for pipeline construction-part 4

\section{APPLICATION EXAMPLE}

The figures of a real case study were not available at the time of this study. Thus, arbitrary figures were assumed for the example. A segment of 1,000 meters of an imaginary pipeline would be studied. There were no irregular conditions or obstacles in this segment. The segment was divided into 100 portions. The material queues ("Soil" queue, "Pipes" queue, "Points2" queue and "Soil2" queue) are each given an initial count of 100. The presumed durations of each activity, used in the model, are presented in table 1. In addition, the hourly costs of all resources are presented in table 2 .

Table 1: Durations of the Activities (mins)

\begin{tabular}{c|cc|c} 
Positioning1 & 10 & Return & 30 \\
\hline Setting1 & 25 & Load_Pipes & 10 \\
\hline Moving & 20 & Haul2 & 20 \\
\hline Positioning2 & 7 & Return2 & 7 \\
\hline Setting2 & 15 & Layout_Pipes & 45 \\
\hline Moving2 & 15 & Weld_Pipes & 13 \\
\hline Clear_Ground & 15 & Inspection & 20 \\
\hline Haul & 35 & ReWeld_Pipes & 60
\end{tabular}




\begin{tabular}{l|lll} 
Lower_Pipes & 15 & Backfill & 25
\end{tabular}

Table 2: Hourly costs of the resources

\begin{tabular}{c|c} 
Survy_Teams & $\mathbf{7 0}$ \\
\hline GPS_Dvc & 300 \\
\hline Tt1S_Dvc & 150 \\
\hline Loaders & 200 \\
\hline Trucks1 & 150 \\
\hline Cranes1 & 70
\end{tabular}

\begin{tabular}{c|c} 
Trucks2 & 200 \\
\hline Cranes2 & 90 \\
\hline WeldCrews & 100 \\
\hline Inspect_Crews & 120 \\
\hline Excavators & 150
\end{tabular}

The model was run 36 times using different scenarios of crews' configuration. These 36 combinations were selected because they are the most common and most realistic combinations in real projects The total duration and unit cost of constructing pipelines that came out from each run is presented in figure 11. The best scenarios are presented in table 3 .

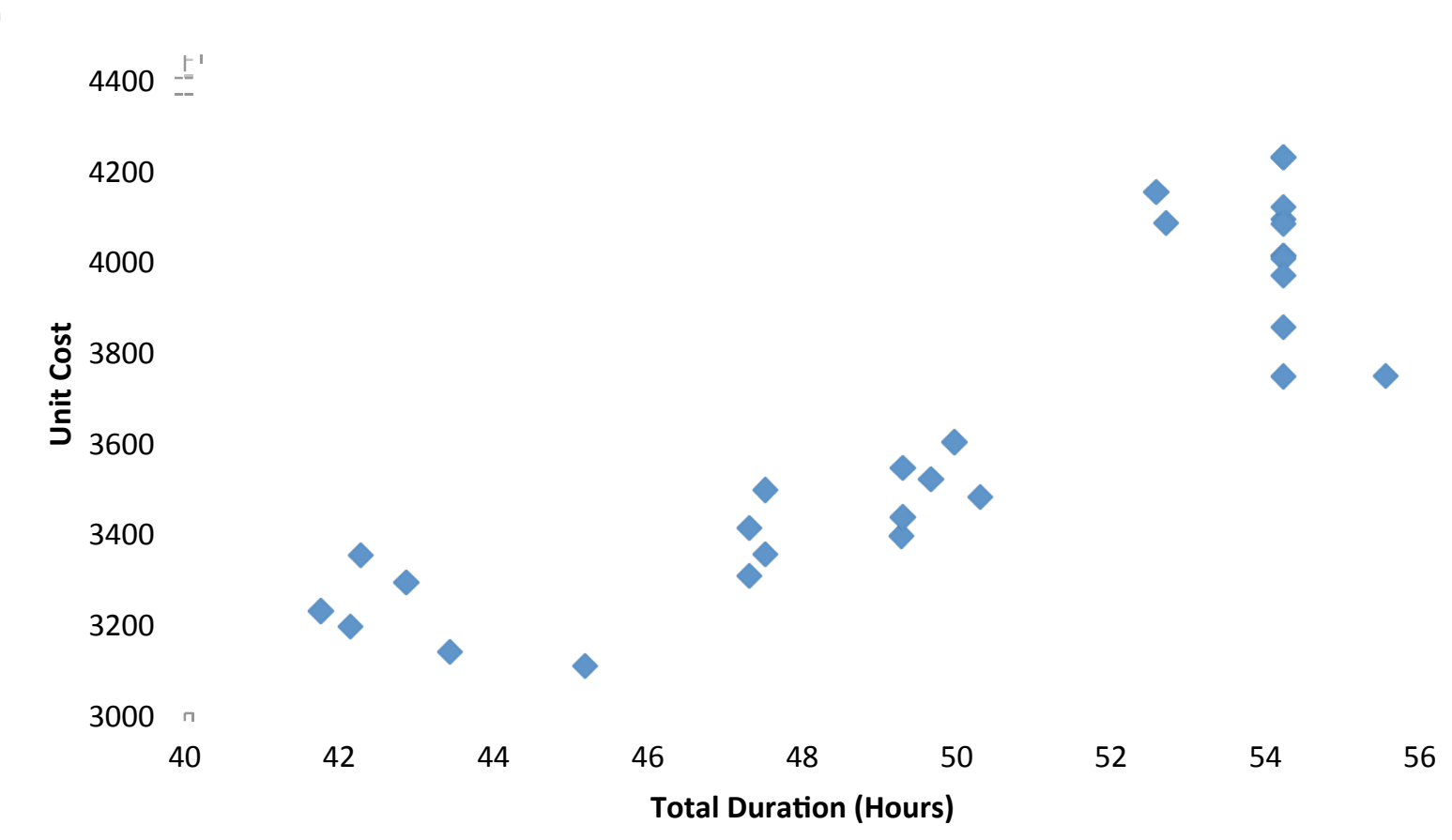

Figure 11: Results of the model 
Companies often collect duration data which can be modeled into typical types of distribution as appropriate for each activity using standard fitting techniques. In general the beta distribution has been shown to be most flexible for modeling duration and cost data as described in Schexnayder et. Al. (2005).

Table 3: Best scenarios' results

\begin{tabular}{|c|c|c|c|c|c|c|c|c|c|c|c|c|c|c|}
\hline & \multirow[b]{2}{*}{$\begin{array}{c}\text { Scenario } \\
\text { No. }\end{array}$} & \multirow[b]{2}{*}{$\begin{array}{c}\text { Unit } \\
\text { Cost } \\
(\$ / 10 \\
m)\end{array}$} & \multirow[b]{2}{*}{$\begin{array}{l}\text { Total Du- } \\
\text { ration } \\
\text { (Hours) }\end{array}$} & \multicolumn{11}{|c|}{ Crews configuration } \\
\hline & & & & 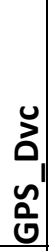 & 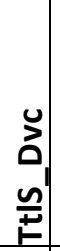 & 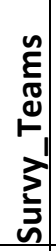 & 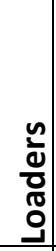 & $\begin{array}{l}\vec{v} \\
\frac{\vec{v}}{v} \\
\vec{v} \\
\vec{n}\end{array}$ & 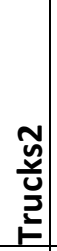 & 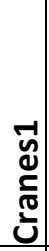 & 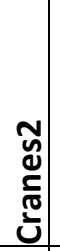 & $\begin{array}{l}\frac{n}{3} \\
\frac{0}{2} \\
\frac{0}{0} \\
3\end{array}$ & 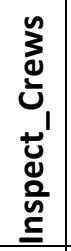 & 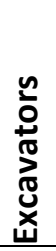 \\
\hline The Least Cost & 34 & 3104.1 & 45.2 & 2 & 4 & 6 & 4 & 7 & 7 & 1 & 6 & 4 & 2 & 5 \\
\hline $\begin{array}{l}\text { The Least Du- } \\
\text { ration }\end{array}$ & 36 & 3224.4 & 41.76 & 2 & 4 & 6 & 4 & 9 & 9 & 1 & 6 & 4 & 2 & 6 \\
\hline
\end{tabular}

\section{CONCLUSIONS AND FUTURE WORK}

Pipeline construction is characterized by complexity, repetitive operations, difficult construction environment, and different construction techniques. These characteristics lead to uncertainty in the estimated duration and cost. This paper presented a tool that aids contractors in planning of pipeline projects using computer simulation. The proposed tool estimates duration and cost required for construction of pipelines.

The paper provided an overview of the tool of simulation. The simulation module is responsible for estimating duration and utilization of resources in each segment in the project. It utilizes EZStrobe as a general purpose simulation engine. However, it is recommended to add an optimization module such as GAs application to the model. An example case was presented in order to demonstrate the important features of the proposed tool and its capabilities in the planning of pipelines.

The model presented in this paper doesn't cover the whole process of onshore pipelines construction. The model could be more realistic, efficient and cover various aspects. In this section, some additions and modifications to the existing model are proposed. Also, a proposal for other models that would work along with this model is presented. The additions and modifications include construction of base camp and pipe yard activities, construction of temporary and permanent access roads, excavation of trenches in rock, the activities of coating the pipeline and applying cathodic protection, and supplying and installing special fixtures and accessories, the hydro-testing of the pipeline. In addition, separate models could be developed for methods of pipe crossings, tie-in with pumps, and valves and measurement stations. In conclusion, these proposals along with the presented model could represent the basis for all future work in this field.

\section{REFERENCES}

AbouRizk, S. M., Ruwanpura, J. Y., Er, K. C., and Fernando, I. (1999). "Special purpose simulation template for utility tunnel construction". Proceedings of the 1999 Winter Simulation Conf., 948-955.

Azadivar, F. (1999). "Simulation optimization methodologies". Proceedings of the 1999 Winter Simulation Conf., Phoenix, 198-204.

Carson, Y., and Maria, A. (1997). "Simulation optimization: methods and applications". Proceedings of the 1997 Winter Simulation Conf., Atlanta, 118-126. 
Halpin, D.W. (1977). "CYCLONE—-method for modeling job site processes". Journal of the Construction Division, ASCE. 489- 499.

Hassan, M. M., and Gruber, S. (2008)."Simulation of concrete paving operations on interstate-74". $J$. Constr. Eng. Manage., 134(1), 2-9.

Hegazy, T. and Kassab, M. (2003). "Resource Optimization Using Combined Simulation and Genetic Algorithms”. Journal of Construction Engineering and Management. 129(6), 698-705.

Martinez J.C. (2001). "EZStrobe - General-Purpose Simulation System Based On Activity Cycle Diagrams". Proceedings of the 2001 Winter Simulation Conference.

Marzouk, M. and Moselhi, O. (2004). "Multiobjective Optimization of Earthmoving Operations". Journal of Construction Engineering and Management, 130(1), 105-113.

Marzouk, M., Zein, H., and El-Said, M. (2006). "A framework for planning and optimizing bridge deck construction using computer simulation". Proceedings of the 2006 Winter Simulation Conf., 20392046.

Shi, J., and AbouRizk, S. M. (1995). "An optimization method for simulating large complex Systems". Eng. Optimiz., 25(3), 213-229.

Tanaka, Y. (1993). "Cycle time simulation of shield-tunneling operation". Proceedings of the 5th Int. Conf. on Computing in Civil and Building Engineering, ASCE, Reston, Va., 1386-1389.

Schexnayder, C., Knutson, K., and Fente, J. (2005). "Describing a Beta Probability Distribution Function for Construction Simulation.” J. Constr. Eng. Manage., 131(2), 221-229.

\section{AUTHOR BIOGRAPHIES}

KHALED NASSAR received his BS and MS degrees with honors from Cairo University in 1992 and 1995 respectively, and his PhD from Virginia Tech, Blacksburg Virginia in 2000. Currently, he is an associate professor of construction and architectural engineering at The American University in Cairo. Prior to joining AUC, he was an assistant professor of construction engineering at Bradley University in Peoria, Illinois, an associate professor at the University Maryland Eastern Shore, USA, as well as serving as the chair of the department of Architectural Engineering at the University of Sharjah, UAE.

HANY ZAHRAN is a master's student in School of Science and Engineering at the American University in Cairo (AUC). He received his B.Sc. from Ain Shams University, Cairo, Egypt. He currently works under Dr. Khaled Nassar. His research interests include simulation and optimization in scheduling and resource utilization problems in construction Industry. His e-mail is hanymz123@aucegypt.edu 